\title{
HUBUNGAN TINGKAT PENGETAHUAN PERAWAT TENTANG RESPONSE TIME DALAM MENENTUKAN TRIASE DIRUANG IGD
}

\author{
M Fikri Ramadhan', Oscar Ari Wiryansyah ${ }^{2}$ \\ Program Studi Sarjana Keperawatan STIKES Mitra Adiguna Palembang \\ Komplek Kenten Permai Blok J No 9-12 Bukit Sangkal Palembang 30114 \\ Email : fikritujuhbelas@gmail.com
}

\begin{abstract}
Abstrak
Instalasi Gawat Darurat (IGD) merupakan titik masuk yang sangat penting untuk pelayanan kesehatan bagi pasien yang membutuhkan penanganan dan perawatan yang mendesak baik itu secara gawat dan darurat. Triase merupakan hal penting dalam merawat dan melakukan penilaian awal pasien di IGD. Pasien gawat darurat harus dilakukan tindakan medik dengan waktu tanggap $<5$ menit. Tujuan penelitian ini untuk mengetahui adanya hubungan tingkat pengetahuan perawat tentang response time dalam menentukan triase di ruang Instalasi Gawat Darurat Rumah Sakit Pusri dan Rumah Sakit Islam AR-Rasyid Palembang. Penelitian ini menggunakan metode analitik dengan pendekatan cross sectional. Sampel dalam penelitian ini berjumlah 30 responden perawat di ruang Instalasi Gawat Darurat Rumah Sakit Pusri dan Rumah Sakit Islam AR-Rasyid Palembang. Sampel diambil dengan menggunakan metode purposive sampling. Hasil penelitian menggunakan Uji Chi-Square dengan derajat kemaknaan 95\% $(\alpha \leq 0,05)$ diperoleh $\rho$ value 0,001 yang berarti $\rho$ value $\leq \alpha(0,05)$. Dengan demikian bahwa adanya hubungan antara tingkat pengetahuan perawat tentang response time dalam menentukan triase. Saran dalam penelitian ini diharapkan dapat melakukan evaluasi secara rutin mengenai pengetahuan perawat tentang response time dalam penanganan pasien di ruang Instalasi Gawat Darurat agar dapat meningkatkan kualitas dalam pelayanan
\end{abstract}

Kata kunci : Response time, Triase

\begin{abstract}
Emergency Department (IGD) is a very important entry point for health care for patients who need urgent treatment and care both emergency and emergency. Triage is important in treating and conducting initial assessments of patients in the ED. Emergency patients must be treated with medical response time $<5$ minutes. The purpose of this study was to determine the relationship between the level of nurses' knowledge about response time in determining triage in the Emergency Room at Pusri Hospital and Palembang AR-Rasyid Islamic Hospital. This research uses analytic method with cross sectional approach. The sample in this study amounted to 30 nurse respondents in the Emergency Room of the Pusri Hospital and Palembang AR-Rasyid Islamic Hospital. Samples were taken using a purposive sampling method. The results of the study used the Chi-Square Test with a significance level of $95 \%(\alpha \leq$ $0.05)$ obtained $\rho$ value 0.001 which means $\rho$ value $\leq \alpha(0.05)$. Thus that there is a relationship between the level of nurse knowledge about response time in determining triage. Suggestions in this study are expected to conduct routine evaluations of nurses' knowledge about response time in handling patients in the Emergency Room so that they can improve the quality of service
\end{abstract}

Key Word : Response time, Triase

Jurnal Kesehatan dan Pembangunan, Vol. 10, No. 19, Januari 2020 


\section{PENDAHULUAN}

Rumah sakit merupakan institusi pelayanan kesehatan yang melaksanakan pelayanan kesehatan perorangan secara lengkap yang menyediakan pelayanan rawat inap, rawat jalan, dan gawat darurat (Musliha, 2010).

Instalasi Gawat Darurat (IGD) merupakan titik masuk yang sangat penting untuk pelayanan kesehatan bagi pasien yang membutuhkan penanganan dan perawatan yang mendesak baik itu secara gawat dan darurat. Gawat suatu kondisi dimana korban harus segera ditolong, apabila tidak segera ditolong maka akan mengalami kecacatan atau kematian.

Ketidaktahuan tentang tata laksana pasien oleh perawat di ruang IGD berpengaruh terhadap kepuasan dan kecemasan pasien, maka dari itu diperlukan triase yang bertujuan untuk menggolongkan dan memprioritaskan pasien yang memerlukan pertolongan terlebih dahulu (Qureshi, 2008).

Response Time merupakan kecepatan dalam penanganan pasien, dihitung sejak pasien datang sampai dilakukan penanganan (Suhartati et al., 2011). Waktu tanggap yang baik bagi pasien yaitu $\leq 5$ menit. Penanganan gawat darurat ada filosofinya yaitu Time Saving it's Live Saving. Artinya seluruh tindakan yang dilakukan pada saatkondisi gawat darurat haruslahbenar-benar efektif dan efisien.Hal ini mengingatkan pada kondisi tersebut pasien dapat kehilangan nyawa hanya dalam hitungan menit saja.

Triage mempunyai tujuan untuk memilih atau menggolongkan semua pasien yang memerlukan pertolongan dan menetapkan prioritas penanganannya.

Triage memiliki fungsi penting di IGD terutama apabila banyak pasien datang pada saat yang bersamaan. Hal ini bertujuan untuk memastikan agar pasien ditangani berdasarkan urutan kegawatannya untuk keperluan intervensi.Triage juga diperlukan untuk penempatan pasien ke area penilaian dan penanganan yang tepat serta membantu untuk menggambarkan keragaman kasus di IGD (Nurhasim, 2015).

Pengetahuan merupakan faktor dominan yang sangat penting untuk terbentuknya tindakan seseorang (Dewi,2010).

Pengetahuan itu sendiri dipengarui oleh faktor pendidikan formal. Pengetahuan sangat erat hubungannya dengan pendidikan, dimana diharapkan bahwa dengan pendidikan yang tinggi maka orang tersebut akan semakin luas pula pengetahuannya. Akan tetapi perlu ditekankan, bukan berarti seseorang yang berpendidikan rendah mutlak berpengetahuan rendah pula. Hal ini mengingat bahwa peningkatan pengetahuan tidak mutlak diperoleh dari pendidikan non formal saja. Akan tetapi dapat diperoleh melalui pendidikan non formal.

Data awal yang diperoleh peneliti pada bulan Februari 2019 di Instalasi Gawat Darurat RS Pusri Palembang, rumah sakit tipe $\mathrm{C}$ dengan jumlah perawat di IGD berjumlah 15 orang yang semuanya telah mengikuti pelatihan dasar kegawat- daruratan, total jumlah kunjungan pasien harian berkisar 50-60 orang dalam 3 bulan yakni bulan November 1.501 pasien, Desember 1.641 pasien, Januari 1547 jadi rata-rata pasien yang berkunjung ke IGD mencapai> 1.500 orang pasien.

Data awal yang diperoleh peneliti pada bulan Februari 2019 di Instalasi Gawat Darurat Rumah Sakit Islam ArRasyid Palembang, rumah sakit tipe C dengan jumlah perawat di IGD berjumlah 15 orang yang semuanya telah mengikuti pelatihan dasar kegawatdaruratan, total jumlah kunjungan pasien harian berkisar 30-50 orang dalam 3 bulan yakni bulan November 1.125 pasien, Desember 1.057 pasien, Januari 1275 jadi rata-rata pasien yang berkunjung ke IGD mencapai $>1.000$ orang pasien. 
Waktu tanggap merupakan hal yang sangat penting untuk diperhatikan dalam menentukan triase di rumah sakit khusus nya di ruang IGD karena waktu tanggap perawat menentukan kualitas dari pelayanan di IGD rumah sakit tersebut. Kurangnya pengetahuan perawat mengenai waktu tanggap dalam menerima pasien di IGD dapat menurunkan angka keselamatan bagi pasien dan juga merugikan keluarga pasien.

Berdasarkan fenomena di atas maka peneliti tertarik untuk melakukan penelitian mengenai "Hubungan Tingkat Pengetahuan Perawat Tentang Response Time dalam Menentukan Triase di Ruang Instalasi Gawat Darurat Rumah Sakit Pusri dan Rumah Sakit Islam ARRasyid Palembang".

\section{METODE PENELITIAN Jenis Penelitian}

Desain penelitian ini menggunakan pendekatan cross sectional, penelitian diukur atau dikumpulkan secara bersamaan, untuk melihat hubungan variabel independen (pengetahuan) dengan variabel dependen (response time).

\section{Waktu dan Tempat Penelitian}

Penelitian ini dilaksanakan di ruang Instalasi Gawat Darurat Rumah Sakit Pusri dan Rumah Sakit Islam ARRasyid Palembang pada bulan Maret-April 2019.

\section{Target/Subjek Penelitian}

Pengambilan sampel pada penelitian ini dilakukan dengan cara non probability sampling menggunakan metode purposive sampling yaitu pengambilan sampel didasarkan pada suatu pertimbangan tertentu yang dibuat oleh peneliti sendiri berdasarkan cirri atau sifatsifat populasi yang sudah diketahui sebelumnya (Notoatmodjo, 2012).

Kriteria Inklusi yaitu : Perawat yang bertugas di ruang Instalasi Gawat Darurat Rumah Sakit, Perawat yang telah mengikuti pelatihan kegawatdaruratan dasar, dan Bersedia menjadi responden dalam penelitian.

\section{Prosedur}

Pengumpulan data melalui dokumen seperti arsip data dari Rumah Sakit Pusri Dan Rumah Sakit Islam ArRasyid Palembang. Peneliti melakukan observasi terhadap response time perawat pada pasien diruang Instalasi Gawat Darurat Rumah Sakit Pusri dan Rumah Sakit Islam AR-Rasyid Palembang, Menjelaskan kepada koresponden yang memenuhi kriteria inklusi tentang penelitian yang akan dilakukan, Menanyakan kepada koresponden apakah bersedia menjadi responden dalam penelitian atau tidak. Serta membagikan lembar persetujuan untuk menjadi responden dalam penelitian (Informed Consent), Peneliti membagikan kuisioner kepada responden dan responden melakukan pengisian kuisioner. Kuisioner diambil kembali 30 menit kemudian.

\section{Data, Instrumen, dan Teknik Pengumpulan Data}

Penelitian ini menggunakan instrument penelitian lembar observasi dan lembar kuesioner tentang response time dan triase.

Data dimasukan dalam master tabel dan pengolahan data dilakukan melalui analisis statistik dengan menggunakan komputer.

\section{Teknik Analisa Data}

Analisis data dalam penelitian ini yaitu analisis univariat yang bertujuan untuk untuk menjelaskan atau mendeskripsikan karakteristik masingmasing variabel yang diteliti, meliputi karakteristik responden, response time perawat dan tingkat pengetahuan perawat tentang response time. Analisis bivariat yaitu analisa yang dilakukan terhadap dua variabel yang diduga atau berkorelasi. Dilakukan uji Chi Square dengan derajat kemaknaan 95\% ( $\alpha 0,05)$. 
Dalam melakukan penelitian, peneliti memperhatikan masalah-masalah etika penelitian yang meliputi: informed consent, anonimity, confidentiality.

\section{HASIL DAN PEMBAHASAN}

Analisis Univariat

Tabel 1. Distribusi Frekuensi Responden Perawat Berdasarkan Tingkat Pendidikan di Instalasi Gawat Darurat Rumah Sakit Pusri dan Rumah Sakit Islam Ar-Rasyid Palembang

\begin{tabular}{lcc}
\hline Tingkat Pendidikan & $(\mathbf{n})$ & $\mathbf{( \% )}$ \\
\hline D III & 23 & $76,7 \%$ \\
S 1 & 6 & $20 \%$ \\
S 2 & 1 & $3,3 \%$ \\
\hline Total & 30 & $100,0 \%$ \\
\hline
\end{tabular}

Sumber : Data primer, 2019

Berdasarkan tingkat pendidikan perawat yang bekerja di Instalasi Gawat Darurat Rumah Sakit Pusri dan Rumah Sakit Islam Ar-Rasyid Palembang didapatkan sebanyak 23 responden lulusan D III Keperawatan, sebanyak 6 responden lulusan S1 Keperawatan dan sebanyak 1 responden lulusan S2 Keperawatan.

Dalam menilai keterampilan seseorang yang dalam hal ini response time perawat, bisa saja dipengaruhi adanya faktor lain. Keadaan ini tergantung dari motivasi perawat dalam mempraktikkan keterampilan kerja yang didapat dari pendidikannya.

Penelitian ini tidak sejalan dengan penelitian yang dilakukan oleh Ali (2014) tentang faktor-faktor yang berhubungan dengan mutu pelayanan keperawatan menyatakan bahwa adanya hubungan antara tingkat pendidikan perawat dengan mutu pelayanan keperawatan.

Tabel 2 Distribusi Frekuensi Responden Perawat Berdasarkan Lama Bekerja di Instalasi Gawat Darurat Rumah Sakit Pusri dan Rumah Sakit Islam Ar-Rasyid Palembang

\begin{tabular}{lcl}
\hline Lama Bekerja & $(\mathbf{n})$ & $(\boldsymbol{\%})$ \\
\hline$<1$ tahun & 6 & $20 \%$ \\
$1-10$ tahun & 19 & $63,3 \%$
\end{tabular}

\begin{tabular}{lrl}
\hline $11-20$ tahun & 5 & $16,7 \%$ \\
\hline Total & 30 & $100,0 \%$ \\
\hline
\end{tabular}

Sumber : Data primer, 2019

Berdasarkan Lama Kerja perawat yang bekerja di Instalasi Gawat Darurat Rumah Sakit Pusri dan Rumah Sakit Islam Ar-Rasyid Palembang didapatkan sebanyak 6 responden yang bekerja selama $<1$ tahun, sebanyak 19 responden yang bekerja selama 1-10 tahun dan sebanyak 5 responden yang bekerja selama 11-20 tahun.

Lama kerja perawat pada suatu rumah sakit tidak identik dengan produktifitas yang tinggi pula. Hal ini didukung oleh teori Robin (2007) yang mengatakan bahwa tidak ada alasan yang meyakinkan bahwa orang-orang yang telah lebih lama berada dalam suatu pekerjaan akan lebih produktif dan bermotivasi tinggi ketimbang mereka yang senioritasnya yang lebih rendah.

Tabel 3 Distribusi Frekuensi Responden Perawat Berdasarkan Keikutsertaan dalam Pelatihan Kegawatdaruratan di Instalasi Gawat Darurat Rumah Sakit Pusri dan Rumah Sakit Islam Ar-Rasyid Palembang

\begin{tabular}{lcc}
\hline Pelatihan & $(\mathbf{n})$ & $\mathbf{( \% )}$ \\
\hline Dasar & 24 & $80,0 \%$ \\
Lanjutan & 6 & $20,0 \%$ \\
\hline Total & 30 & $100,0 \%$ \\
\hline
\end{tabular}

Sumber : Data primer, 2019

Berdasarkan keikutsertaan dalam pelatihan kegawatdaruratan menunjukkan bahwa seluruh perawat di Instalasi Gawat Darurat Rumah Sakit Pusri dan Rumah Sakit Islam Ar-Rasyid Palembang pernah mengikuti pelatihan kegawatdaruratan dasar yaitu sebanyak 27 (90,0\%).

Tabel 4 Distribusi Frekuensi Responden Perawat Berdasarkan Tingkat Pengetahuan di Instalasi Gawat Darurat Rumah Sakit Pusri dan Rumah Sakit Islam Ar-Rasyid Palembang 


\begin{tabular}{lcl}
\hline Tingkat & & \\
\hline Pengetahuan & $(\mathbf{n )}$ & $\mathbf{( \% )}$ \\
\hline Baik & 22 & $73,3 \%$ \\
Cukup & 5 & $16,7 \%$ \\
Kurang & 3 & $10 \%$ \\
\hline Total & 30 & $100,0 \%$
\end{tabular}

Sumber : Data primer, 2019

Berdasarkan tingkat pengetahuan menunjukkan bahwa sebagian besar responden memilki tingkat pengetahuan yang baik yaitu sebanyak $22(73,3 \%)$ di Instalasi Gawat Darurat Rumah Sakit Pusri dan Rumah Sakit Islam Ar-Rasyid Palembang.

Dalam memberikan bantuan pelayanan gawat darurat petugas harus mempunyai 3 unsur kesiapan, antara lain adalah kesiapan pengetahuan dan keterampilan karena erat kaitannya dengan upaya penyelamatan langsung terhadap pasien. (Widiasih, 2008).

\section{Analisis Bivariat}

Tabel 5 Hubungan Tingkat Pengetahuan Perawat dengan Response time di Instalasi Gawat Darurat Rumah Sakit Pusri dan Rumah Sakit Islam Ar-Rasyid Palembang

\begin{tabular}{|c|c|c|c|}
\hline Tingkat Pengetahuan & \multicolumn{2}{|c|}{ Response Time } & $\bar{\rho}$ \\
\hline $\begin{array}{l}\text { value } \\
\text { valus }\end{array}$ & Cepat & Lambat & \\
\hline Baik & 22 & 0 & \\
\hline Cukup & 4 & 1 & \\
\hline 0,001 & & & \\
\hline Kurang & 1 & 2 & \\
\hline
\end{tabular}

Sumber : Data primer, 2019

Berdasarkan tingkat pengetahuan perawat yang bekerja di Instalasi Gawat Darurat Rumah Sakit Pusri dan Rumah Sakit Ar-Rasyid Palembang didapatkan sebagian besar perawat memilki tingkat pengetahuan yang baik yaitu sebanyak 22 $(73,3 \%)$ responden, sebanyak 5 responden yang memilki tingkat pengetahuan cukup dan sebanyak 3 responden yang memilki tingkat pengetahuan kurang

Dari hasil uji Chi-Square diperoleh $\rho$ value $(0,001<0,05)$ menunjukkan bahwa adanya hubungan yang bermakna antara tingkat pengetahuan perawat dengan response time perawat pada penanganan pasien gawat darurat.

Hasil penelitian ini sejalan dengan penelitian Hasmoko (2008) tentang analisis faktor-faktor yang mempengaruhi kinerja klinis perawat berdasarkan penerapan system pengembangan manajemen kinerja klinis rumah sakit menyatakan bahwa pengetahuan mempengaruhi kinerja klinis perawat.

Berdasarkan penelitian Rumampuk et al (2019) yang berjudul Hubungan Ketepatan Triase Dengan Response Time Perawat Di Instalasi Gawat Darurat Rumah Sakit Tipe $\mathrm{C}$ dengan menggunakan uji fisher's exact test pada tingkat kemaknaan 95\%, diperoleh nilai signifikan $\mathrm{p}=0,003$ atau lebih kecil dari 0,05 (0,003) yang menunjukkan bahwa terdapat hubungan antara ketepatan triase dengan response time perawat di IGD rumah sakit tipe $\mathrm{C}$.

Hal ini berbeda dengan penelitian yang dilakukan oleh Maatilu et al (2014) yang berjudul Faktor-Faktor Yang Berhubungan Dengan Response Time Perawat Pada Penanganan Pasien Gawat Darurat Di IGD RSUP Prof. Dr . R. D. Kandou Manado yang menyebutkan bahwa tidak adanya hubungan antara tingkat pengetahuan perawat dengan response time dalam penanganan pasien gawat darurat.

Berdasarkan hasil penelitian dan pembahasan peneliti berpendapat bahwa pengetahuan responden tentang response time sudah baik karena data yang didapat menunjukkan mayoritas responden memilki pengetahuan baik $(73,3 \%)$. Pengetahuan yang didapat dipengerahui melalui pelatihan-pelatihan yang dilakukan sehingga dapat menambah pengetahuan responden.

\section{KESIMPULAN}

Response time perawat di Instalasi Gawat Darurat Rumah Sakit Pusri dan Rumah Sakit Islam Ar-Rasyid Palembang rata-rata cepat yaitu kurang dari 5 menit. 
Tingkat pengetahuan perawat tentang response time sudah sangat baik karena sebagian besar perawat memiliki tingkat pengetahuan yang baik di Instalasi Gawat Darurat Rumah Sakit Pusri dan Rumah Sakit Islam Ar-Rasyid Palembang. Terdapat hubungan yang signifikan antara response time perawat dengan tingkat pengetahuan perawat di Instalasi Gawat Darurat Rumah Sakit Pusri dan Rumah Sakit Islam Ar-Rasyid Palembang.

\section{SARAN}

Sebagai bahan masukan bagi
peneliti yang akan datang untuk
melakukan penelitian lebih mendalam
tentang hubungan tingkat pengetahuan
perawat terutama mengenai teori-teori
terbaru mengenai instalasi gawat darurat
dengan menggunakan metode analisis
yang berbeda dan jumlah sampel yang
lebih banyak.

\section{DAFTAR PUSTAKA}

Adryaniet al, 2015. Analisis peran perawat triage terhadap waiting time dan length of stay pada ruang triage di IGD RS dr Saiful Anwar Malang.

Amelia,2013.

Prinsip

Etika

Keperawatan.Jogjakarta:D-Medika

Dewi,2010.Pengetahuan, Sikap, dan Perilaku Manusia. Yogyakarta:Nuha Medika.

Faizin, A \& Winarsih. 2008. Hubungan tingkat pendidikan dan lama kerja perawat terhadap kinerja perawat di Rumah Sakit Umum Pandan Arang Kabupaten Boyolali. Berita Ilmu Keperawatan ISSN 1979-2697. Vol 1(3) September 137-142

Kartikawati, N. Dewi.2013.Buku Ajar Dasar-Dasar Keperawatan Gawat Darurat. Jakarta: Salemba Medika

Keputusan Menteri Kesehatan RI (2009) Standar Instalasi Gawat Darurat (IGD) Rumah Sakit. Jakarta: Menteri Kesehatan RI
Khairina,I., et al,.2018.Faktor-Faktor Yang Berhubungan Dengan Pengambilan Keputusan Perawat Dalam Ketepatan Triase Di Kota Padang. Fakultas Keperawatan Universitas Andalas Indonesia.Indonesia Journal For Health Science Vol.02, No.01

Lontoh, C.2013. Pengaruh Pelatihan Teori Bantuan Hidup Dasar Terhadap Pengetahuan Resusitasi Paru SiswaSiswi SMAN 1 Toili. (Diakses 14 Juli 2014. https://ejournal.unsrat.ac.id/index.ph $\mathrm{p} / \mathrm{jkp} / \mathrm{article} / \mathrm{view} / 2173$ )

Mardalena, Ida. 2017.Asuhan Keperawatan Gawat Darurat.Yogyakarta: Pustaka Baru Press

Maatilu, V, et al,.2014.Faktor-Faktor Yang Berhubungan Dengan Respon Time Perawat Pada Penanganan Pasien Gawat Darurat Di IGD RSUP Prof.Dr.R.D.Kandou Manado. Fakultas Kedokteran Program Studi Ilmu Keperawatan Universitas Sam Ratulangi Manado. E-journal keperawatan $(e-K e p)$

Musliha.2010.Keperawatan Gawat

Darurat. Yogyakarta: Nuha Medika

Notoatmodjo, Soekidjo. 2012.Metode penelitian kesehatan.Jakarta : PT Rineka Cipta

Nursalam.2009. Konsep Dan Penerapan Metodologi Penelitian Ilmu Kesehatan.Jakarat: Salemba Medika

Nurhasim, 2015.Pengetahuan Perawat Tentang Response Time Dalam Penanganan Gawat Darurat Diruang Triase RSUD Karanganyar.

Romiko et al,.2018.Faktor-Faktor Yang Berhubungan Dengan Lama Waktu Tunggu Pasien di IGD RS Muhammadiyah Palembang 
Sastrohadiwiryo. S., B.2002. Manajemen Tenaga Kerja Indonesia;

Pendekatan Administrasi dan Operasional. Jakarta: Bumi Aksara

Setiadi. (2013). Konsep Dan Praktek Penulisan Riset Keperawatan (Ed.2) Yogyakarta: Graha Ilmu

Sitorus \& Panjaitan. 2011. Manajemen Keperawatan: Manajemen Keperawatan di Ruang Rawat, ed 1. Jakarta: CV Sagung Seto

Sugiyono.(2016). Metode Penelitian Kuantitatif Kualitatif dan Kombinasi (Mixed Methods). Bandung: Alfabeta.

Suhartati, S.Kep.M.Kes, 2011. Standar Pelayanan Keperawatan Gawat Darurat Di Rumah Sakit: Jakarta.

Sutawijaya, Bagus Risang. 2009. Gawat darurat Panduan Kesehatan Wajib di Rumah Anda. Yogyakarta :Aulia Publishing

Widiasih, Ni Luh. 2008. Peran Perawat Anastesi dalam Kegawatdaruratan Surabaya (Makalah disampaikan pada Seminar Kursus Penyegaran Keperawatan Anestesi) (hal 27-34)

Wilde, E. T. 2009. Do Emergency Medical Sytem Response Times Matter for Health Outcomes. Colombia University:NewYork 